\title{
Netnografia: incursões metodológicas na cibercultura
}

\author{
Paula Jung Rocha ${ }^{1}$ \\ Feevale \\ paula@opiniao.com.br \\ Sandra Portella Montardo \\ Feevale \\ sandramontardo@feevale.br
}

\begin{abstract}
Resumo: $O$ presente artigo tem por objetivo apresentar a netnografia como alternativa metodológica de pesquisa científica no campo da comunicação a partir da constatação de que muitos objetos de estudo localizam-se no ciberespaço. Para tanto, o texto estabelece a relação entre comunicação e cibercultura e está organizado da seguinte forma: traça-se um paralelo metodológico entre a comunicação e outras ciências sociais, elabora-se uma relação entre a cibercultura e a antropologia, através do conceito de não-lugar de Marc Augé (1994) e se mostra algumas aplicações científicas e mercadológicas desse método.
\end{abstract}

Palavras-chave: Cibercultura, comunicação, antropologia, metodologia e etnografia.

Abstract: This article presents the netnographic method as a methodlogical alternative for researching in cyberspace field. With this purpouse it makes a relation between communications and cyberculture studies. In the first part there is a presentation about communications and other social sciences. After it discusses aspects from cyberculture and anthropology by a concept formulated in Marc Augé academic work called non-place. The paper shows some application of this method in cyberspace.

\footnotetext{
${ }^{1}$ Prof. Ms. Paula Jung Rocha. Jornalista. Professora do Centro Universitário Feevale/RS. Doutoranda em Comunicação Social no PPGCOM Famecos/PUCRS. ${ }^{2}$ Prof. Dr. Sandra Portella Montardo. Publicitária. Professora do Centro Universitário Feevale.
} 
Key-words: cyberculture, communications, anthropology, methodology and ethnography.

Resumé: Cet article se propose de présenter la netnographie comme une alternative méthodologique au champ de la communication parce que il y a beaucoup des objets d'étude de ce champ dans le cyberespace. Pour cela, le texte fixe la relation entre la communication et la cyberculture et est divisé de la façon suivante : 1) établissement d'un paralléle méthodologique entre la communication et les autres sciences sociales ; 2) élaboration d'une relation entre la cyberculture et l'anthropologie, à travers du concept de non-lieu de Marc Augé (1994) ; 3) présentation de quelques applications scientifiques et de marketing de ce méthode.

O questionamento despertado em torno da cibercultura lembra aquele que ronda com insistência o campo de pesquisa da comunicação, em termos da imprecisão de seus limites e de sua abrangência. De fato, emerge do senso comum e das fontes que irrigam o imaginário contemporâneo, retroativamente, a intuição de que a cibercultura se impõe como matriz de sentido contemporânea. Nota-se, quanto a isso, que a cibercultura pauta e é pautada por temas da sociedade, porque se imiscui nas práticas cotidianas. Saída das páginas dos romances de ficção científica ${ }^{3}$, a cibercultura ganha a vida no dia a dia, dinamizando o imaginário contemporâneo e concretizandose em práticas. Na medida em que estampa capas de revistas de variedades,

\footnotetext{
$3 \mathrm{O}$ termo ciberespaço foi utilizado pela primeira vez pelo romancista William Gibson no romance de ficção científica Neuromancer, mas o seu sentido mais específico relacionado às novas tecnologias pode ser encontrado em Pierre Lévy, segundo o qual "o ciberespaço (também chamado de rede) é o novo meio de comunicação que surge da interconexão mundial dos computadores. O termo especifica não somente a infraestrutura material da comunicação digital, mas também o universo oceânico de informações que ela abriga, assim como os seres humanos que navegam e alimentam esse universo" (LÉVY, 1999, p. 17).
} 
invade as telas de cinema, circula pela Internet, pode-se dizer que a cibercultura ocupa um lugar privilegiado como matriz de sentido contemporânea.

Um exemplo pode ser encontrado no encarte especial da Revista Veja, de dezembro de 2005, chamado Natal Digital. Nesta publicação, além de interesses claramente mercadológicos vê-se que os assuntos, antes especialmente ligados aos experts em informática, agora estão sendo foco de interesse também dos leitores comuns. A entrevista com o filósofo norteamericano, Ted Nelson, que cunhou o termo hipertexto e esteve envolvido com os primórdios da web (a partir de uma conversa com Tim Bernners-Lee, este sim o pai da World Wide Web), é um dos indícios de quanto esta temática ultrapassa os jargões tecnoburocratas e chama atenção dos navegadores.

Da mesma forma que a cibercultura está por toda parte, costuma-se concordar sobre o fato de que tudo seja comunicação. A relação institucional entre a comunicação e a cibercultura pode ser verificada na existência de grupos de trabalho e de núcleos de pesquisa em congressos e em simpósios da área da comunicação ${ }^{4}$. Da mesma forma, o interesse que essa questão suscita se manifesta no nome de algumas linhas de pesquisa oferecidas por programas de pós-graduação no Brasil, além de se expressar na formação de grupos de discussão a respeito da matéria e de gerar publicações a respeito da mesma.

4 O Congresso anual da Sociedade Brasileira de Estudos Interdisciplinares da Comunicação (INTERCOM), conta com o Núcleo de Pesquisa "Tecnologias da Informação e da Comunicação", subdividido em quatro subgrupos: Internet, Hipermídia, Sociabilidade Virtual e Tecnologia e Cultura. Por sua vez, o encontro anual da Associação Nacional de Programas de Pós-Graduação discute sobre cibercultura no grupo de trabalho denominado "Tecnologias Informacionais de Comunicação e Sociedade”. 
Interessante notar que a cibercultura como tema busca denotar uma realidade bem mais ampla do que aquela abrangida pela comunicação. Por isso, observa-se que é pela área de pesquisa da comunicação, e também da sociologia, da filosofia e da antropologia que se evoca o conjunto de fatos reais e imaginários que se alinham sob este conceito, com o que a comunicação se torna um veículo para a discussão dessa matriz de sentido.

Como se vê, ainda que o tema da cibercultura seja facilmente encontrado nas práticas sociais, além de estar institucionalmente legitimado no campo de pesquisa da comunicação, tanto este quanto a comunicação continuam a enfrentar o desafio de sua formatação intelectual, sendo que ainda são raros artigos que se destinem especificamente a abordar essa relação do ponto de vista metodológico (referências nesse sentido estão na última seção desse texto). Frente a isso, este artigo pretende caracterizar e ilustrar a netnografia como uma das ferramentas metodológicas capazes de proporcionar o acesso dos pesquisadores da área às caracterizações específicas da contemporaneidade, sobretudo a virtualidade, a desmaterialização e a digitalização de conteúdos, formas, relacionamentos, produtos e etc. Para tanto, é preciso, antes, verificar aspectos da questão metodológica nas ciências sociais como um todo.

\section{Sobre a metodologia na Comunicação e nas outras Ciências Sociais}

A discussão acerca da reivindicação de um estatuto científico para a comunicação, enquanto delimitação de um campo científico da comunicação, tem sido uma temática permanente entre os investigadores dessa área na América Latina desde meados dos anos oitenta. Questionamentos nesse sentido, associados a uma crise dos paradigmas, também vem sendo postos pelas Ciências Sociais como um todo.

Um olhar sobre a história das teorias da comunicação, contada aqui por Armand e Michèlle Mattelart (1999), revela o interesse das mais diferentes disciplinas pelos processos comunicacionais. Segundo esses autores, a 
filosofia, a história, a geografia, a psicologia, a sociologia, a etnologia, a economia, as ciências políticas, a biologia, a cibernética e as ciências cognitivas são exemplos de disciplinas que, de uma forma ou de outra, valemse de questões da comunicação em suas investigações.

Essa versatilidade do campo da comunicação tem suscitado a pressuposição de modelos de cientificidade que lhe garantam legitimidade científica. Em vista disso, os campos de saber entre os quais a comunicação transita foram solicitados a muni-la com o aparato teórico e científico de cada um desses campos, "por meio de analogias." (MATTELART, 1999, p. 9).

A partir de uma perspectiva histórica, Martino (2005) percebe na trajetória do campo comunicacional um deslocamento de sentido da interdisciplinaridade, em termos de que esta é vista, num primeiro momento, como condição natural de um campo em formação para se tornar um estatuto epistemológico (ou anti-epistemológico).

Quanto ao cruzamento de saberes em torno da comunicação, Fuentes Navarro faz notar que é preciso "reestabelecer a discussão teórica, mas a partir de uma perspectiva epistêmica e referencial mais ampla que o âmbito específico da teoria." (FUENTES NAVARRO, 1996, p. 11). Ainda nesse sentido, o mesmo autor, com outros (Krippendorff, Jensen e Jankowski e Giddens), remete à emergência de novas sínteses quanto à teoria e à metodologia "na confluência entre ciências sociais e humanidades." (FUENTES NAVARRO, 1997, p. 219).

De maneira mais direta, Vizer (2005) identifica e enfatiza o compartilhamento de certas categorías entre a comunicação e a análise social. Ao entender a comunicação como processo de construção de sentido, o autor relaciona vários aspectos desse processo em interface com outras ciências sociais e humanas que podem ser captados via análise de discurso, análise dos meios e das Tecnologías de Informação e Comunicação. Finalmente, Vizer propõe: 


\begin{abstract}
Para superar o impasse e a fragmentação do campo considero bastante frutífera a construção de um marco teórico sóciocomunicacional - ou sócioantropológico e comunicacional que permita compartilhar categorías e problemáticas de análise que articulem entre si a hipótese sobre a interdependencia entre processos e práticas sociais fundantes como os que se apresentam aquí. (VIZER, 2005, cd-rom)
\end{abstract}

Entre as possíveis aplicações dessas categorias, o autor destaca: dispositivo de análise de diagnóstico - sócioanálise- para ser aplicado em organizações, análise de processos discursivos sobre os meios audiovisuais e as tecnologias de informação e de comunicação.

Faz-se pertinente, portanto, relacionar questões abordadas recentemente por Marc Augé, no campo da antropologia, e que podem ser tomadas de empréstimo pela comunicação, ao menos quando esse campo de interesse abordar relações sociais na cibercultura.

\title{
Não-lugar: o encontro entre a Antropologia e a Cibercultura
}

A inquietação que persegue este estudo está presente desde o momento em que se pretende tratar os fenômenos contemporâneos ligados à comunicação. Ao partir de uma constatação temporária de que a cibercultura é uma matriz de sentido destes tempos, como já se falou anteriormente, há de se pensar o modo pelo qual o olhar científico deve se guiar na análise de tais ocorrências.

O fato é que as recorrentes pesquisas ao campo da antropologia (devido à legitimação dos instrumentos de pesquisa de campo que atuam sobre o local) levam a considerações, importantes, ainda que não sejam inéditas, quando se trata de investigar os elementos que descrevem a consolidação de uma era fortemente permeada pela cibercultura, ou seja, pela desterritorialização que remete justamente ao não pertencimento físico e presencial do lugar. Uma época em que pode ser comum, em um primeiro 
momento, relacionar a oposição online/virtual versus offline/real. Porém em que em um aprofundamento teórico tal sensação fragiliza-se.

Pode-se dizer que o conceito de não-lugares de Augé (1994) fornece pistas evidentes da conexão da antropologia com a cibercultura, ainda que o autor não a tenha explicitado (o texto original é de 1992, antes, portanto, da popularização da internet pelo mundo). A título de contraponto, o autor, conceitua lugar a partir de três características comuns, quais sejam, ser pretensamente identitários, relacionais e históricos. Nas palavras do autor (1994): "finalmente, o lugar é necesariamente histórico a partir do momento em que, conjugando identidade e relação, ele se define por uma estabilidade mínima. (AUGÉ, 1994, p.53). Quanto aos não-lugares, a citação que segue é bastante esclarecedora:
A hipótese aqui defendida é a de que a supermodernidade é produtora de não-lugares, isto é, de espaços que não são em si lugares antropológicos e que, contrariamente à modernidade baudelairiana, não integram os lugares antigos: estes, repertoriados, classificados e promovidos a 'lugares de memória', ocupam aí um lugar circunscrito e específico (AUGÉ, 1994, p.73)

Como exemplo de não-lugares, o autor cita: ferroviárias, rodoviárias e domicílios móveis (meios de transporte) tais como aviões, trens, ônibus, aeroportos, estações, grandes cadeias de hotéis, parques de lazer, e, finalmente, "as grandes superfícies de distribuição, a meada complexa, enfim, redes a cabo ou sem fio, que mobilizam o espaço extraterrestre para uma comunicação tão estranha que muitas vezes só põe o indivíduo em contato com uma outra imagem de si mesmo" (AUGÉ, 1994, p.75). O autor (1994) ainda destaca que um não-lugar pode existir como lugar, destacando ainda que lugar e não-lugar são polaridades fugidias: o primeiro nunca é completamente acabado e o segundo nunca se realiza completamente.

Um ponto importante a ser destacado é que o usuário do não-lugar mantém com ele uma relação contratual (comércio, trânsito, comércio, lazer). Esses não-lugares têm por característica serem definidos por palavras ou 
textos, os quais propõem ao usuário, de forma prescritiva, informativa, proibitiva, o seu próprio "manual de utilização". Para tanto, vale-se de uma variedade de códigos ou, até, mesmo, da língua natural.

Em termos de ciberespaço, pode-se dizer que o mecanismo de mediação se dá por meio da interatividade do usuário frente a interfaces gráficas. Lemos (1997, internet) propõe que a interatividade digital é um tipo de relação tecno-social, consistindo no diálogo entre homens e máquinas (baseadas no princípio da microeletrônica), cujo contato é permitido por 'interfaces gráficas', em tempo real. Com a tecnologia digital, o usuário pode interagir não só com o objeto (a máquina ou a ferramenta), mas também com a informação, com o conteúdo, seja da televisão interativa digital, seja com os ícones das interfaces gráficas dos microcomputadores.

Essa característica da interatividade digital, de permitir a interação com a informação (“cuja forma física escapa à nossa escala de percepção”, segundo Manzine, apud Lemos, 1997, internet) e não apenas com o suporte técnico, tende a afetar de maneira substancial as relações entre sujeito e objeto na contemporaneidade.

Pode-se dizer que são as interfaces gráficas meios (hardware e software) pelos quais se dá à interatividade entre os homens e máquinas digitais. $\mathrm{O}$ aperfeiçoamento das interfaces gráficas pode ser flagrado na variedade de formas possíveis de execução de funções em determinados suportes técnicos (internet, celular, caixa automático, centrais telefônicas, etc.) e também nas condições cada vez mais fáceis de navegabilidade nos mesmos. Finalmente, pode-se dizer que a vocação da interface é "traduzir, articular espaços, colocar em comunicação duas realidades diferentes" (Bairon, 1995, apud LEMOS, 1997, Internet). A realidade virtual é um extremo desse processo. A próxima seção traz considerações sobre cibercultura e aplicações de netnografia. 


\section{Netnografia e etnografia virtual}

Antes de discutir este tema propriamente dito, vale ressaltar que as pesquisas para este trabalho basearam-se em referências bibliográficas (tanto em bibliotecas presenciais como em informações disponíveis na rede). O que se pode notar com maior relevância é a utilização do termo etnografia virtual por pesquisadores da área da comunicação e de netnografia, principalmente, por estudiosos da área de marketing digital. Optou-se por nomear, aqui neste texto, tal metodologia como netnografia conforme utilizado pela pesquisadora Simone Pereira de Sá, como será visto a seguir.

Uma das possibilidades de se estudar o imaginário virtual e seus atores sociais se faz pelo método da observação. Assim como é comum para a antropologia, a observação no ciberespaço é relevante. Porém devido à natureza desterritorializada do ciberespaço, o que se pergunta é de que forma fazer a observação participante à distância. A premissa básica da aproximação ao objeto de estudo merece, então, um redirecionamento.

Faz-se pertinente retomar alguns pontos sobre o campo da antropologia/etnografia. Para isto o pesquisador Clifford Geertz, o qual é favorável a uma "descrição densa" como principal conceito de etnografia esclarece que,

fazer etnografia é como tentar ler (no sentido de construir uma leitura de) um manuscrito estranho, desbotado, cheio de elipses, incoerências, emendas suspeitas e comentários tendenciosos, escrito não com os sinais convencionais do som, mas com exemplos transitórios de comportamento modelado. (GEERTZ, 1989, p. 20)

Outra concepção de etnografia pode ser encontrada em Aguirre Baztán, segundo o qual "etnografia é o estudo descritivo da cultura de uma comunidade, ou de algum de seus aspectos fundamentais, sobre a perspectiva de compreensão global da mesma” (BAZTÁN, 1995, p.3).

Este trabalho objetiva refletir quanto ao cumprimento de um roteiro metodológico condizente com uma atitude que privilegie uma "antropologia 
do próximo”. Expressão teorizada pelo antropólogo Marc Augé (1994), o qual situa sua posição de que "a antropologia sempre foi uma antropologia do aqui e do agora" porque o autor/pesquisador, segundo o autor, deve ser o etnólogo que se encontra em algum lugar (seu aqui do momento) e que descreve aquilo que observa ou escuta naquele momento" (AUGÉ, 1994, p. 56).

Tal argumentação está associada à problematização que pretende este texto uma vez que ao nomear o presente como cibercultura entende-se que grande parte das pesquisas científicas estão sendo feitas hoje a partir da sua análise. E ainda, se segundo o antropólogo, "toda etnologia supõe um testemunho direto de uma atualidade presente" (AUGÉ, 1994, p.75), cabe ao pesquisador-etnógrafo contemporâneo escolher corretamente o que lhe é mais apropriado, em termos de técnicas e ferramentas de pesquisa, para auxiliá-lo como testemunha de um mundo que também se desenrola no ciberespaço e, que tende a cada dia, diminuir concretamente a fronteira entre real e virtual.

Quanto à questão da escolha do método etnográfico, portanto da utilização da teoria antropológica como pano de fundo para este artigo que faz parte de uma pesquisa na área da cibercultura, segue uma citação de Augé que legitima esta proposta e, principalmente enaltece a ciência do homem (Antropologia) na contemporaneidade e não apenas numa época em que Antropologia se prestava, quase que exclusivamente, ao estudo dos povos distantes e primitivos, como se sabe.
A questão que se coloca, primeiro, a propósito da contemporaneidade próxima não é saber se e como se pode pesquisar num grande conjunto, numa empresa ou numa colônia de férias (bem ou mal, chegar-se-á a isso), mas saber se há aspectos da vida social contemporânea que aparecem hoje como se originando de uma investigação antropológica - da mesma maneira que as questões de parentesco, da aliança, do dote, da troca etc. impuseram-se, primeiro, à atenção (como objetos intelectuais) dos antropólogos do distante. (AUGÉ, 1994, p. 20) 
Portanto, é pertinente compreender que se passa por um período de transição da modernidade para a pós-modernidade, e considerar os indicativos de tal mudança. $\mathrm{Na}$ (re)formulação das variáveis contemporâneas, se manifestam as cristalizações sociais, tecnológicas, políticas e econômicas, que constituem as formas "formantes" que influenciam o fundo e o imaginário da atualidade. Os usuários dos não-lugares estão produzindo e sendo alimentados pelo imaginário da cibercultura.

Visto que as características da contemporaneidade evidenciam explicitamente a supressão do tempo e do espaço, faz-se importante abordar esta problemática. No que concerne às novas tecnologias de comunicação e de informação é sabido que uma das principais contribuições das invenções, ao longo, da história da humanidade é de tentar controlar o tempo e expandir o seu alcance no espaço.

A globalização inaugura o pensamento da desterritorizalição dos valores, mercadorias e também das pessoas. A própria noção de real e de virtual, amplamente discutida também se torna alvo de relativizações. $\mathrm{O}$ pesquisador Otávio Ianni lança sua opinião sobre o fenômeno contemporâneo, pós-moderno ou não, para o fato de que as categorias de tempo e de espaço evidenciam fragilidades na conceituação. Sobre esse ponto, o autor complementa:

\footnotetext{
É assim que a desterritorialização aparece como um momento essencial da pós-modernidade, um modo de ser isento de espaços e tempos, no qual se engendram espaços e tempos inimagináveis. É como se o mundo se mostrasse povoado de sucedâneos, simulacros, fetiches autonomizados, reificados, alheios ao cerne das coisas, isentos da tensão e aura do real. (IANNI, 1996, p. 105)
}

Conforme Augé (1994), a exploração do espaço e do tempo se torna aos poucos um desafio para homem, que mesmo ao descobrir a infinidade do universo persiste no desejo de ubiqüidade com consciência dos limites. Nas palavras do autor, tem-se que: 
Do excesso de espaço poderíamos dizer, (...) que é correlativo do encolhimento do planeta: dessa colocação à distância de nós mesmos à qual correspondem às performances dos cosmonautas e a ronda de nossos satélites. Num certo sentido, nossos primeiros passos no espaço reduzem o nosso ponto ínfimo cujas fotos feitas por satélite dão-nos justamente a medida exata. $\mathrm{O}$ mundo, porém, no mesmo tempo, abre-se para nós.(AUGÉ, 1994, p. 34)

Ao levar em consideração fundamentalmente a premissa do antropólogo Marc Augé sobre o que chama de "etnologia da solidão", cuja manifestação mais radical no presente seria a relação que o homem estabelece com o computador e seus serviços, ou seja, a virtualidade, principalmente a internet, pode-se assim associar com a consolidação de um não-lugar, neste caso, o ciberespaço ${ }^{3}$. O autor não utiliza o termo pós para classificar o presente (exemplo, pós-modernidade). Prefere acrescentar o prefixo super, que faz menção ao excesso.

A supermodernidade (que procede simultaneamente das três figuras do excesso que são a superabundância factual, a superabundância espacial e a individualização das referências) encontra naturalmente sua expressão completa nos não-lugares. Por estes, ao contrário, transitam palavras e imagens que retomam raiz nos lugares ainda diversos onde os homens tentam construir uma parte de sua vida cotidiana (AUGÉ, 1994, p. 100).

Noutro ponto do texto, o autor acrescenta que "é no anonimato do nãolugar que se experimenta solitariamente a comunhão dos destinos humanos" (1994, p.110). Pode-se com esta citação de Augé caracterizar a paradoxal sociedade contemporânea, pois ao mesmo tempo em que o não-lugar é solitário e contratual, vê-se que a apropriação da cultura pela cibernética, ou seja, a cibercultura promove também no ciberespaço situações de socialidade em rede. O sucesso de sites de relacionamento, Orkut e derivados, são provas desta potencialização de sentimentos. Porque também se constituí em uma possibilidade de comunhão, de agregação virtual, nem por isso menos real,

\footnotetext{
7 Esta associação do conceito de não-lugar proposto por Marc Augé e do conceito de ciberespaço, ou espaço virtual é uma das constatações que a autora se permitiu fazer por acreditar nas semelhanças entre os não-lugares apontados por Augé e as discussões a respeito da natureza do ciberespaço.
} 
dos indivíduos. Assim, pode-se fazer a associação do imaginário pós-moderno ser coletivo (proposto por Maffesoli) e, ao mesmo tempo, não excluir os apontamentos de Augé sobre a prevalência do individualismo na contemporaneidade.

\section{Netnografia: definição e possibilidades práticas de aplicação}

Segundo Kozinets ${ }^{4}$ (2002) a netnografia é definida como um método de pesquisa derivado da técnica etnográfica desenvolvida no campo da antropologia e, costuma-se dizer que a netnografia tem conhecido um crescimento considerado devido à complexidade das experiências da sociedade digital. Este método é constantemente utilizado por pesquisadores das áreas da comunicação, do marketing, da antropologia e da sociologia. Nota-se que muitos sites descrevem netnografia como o monitoramento de comunidades on-line a fim de se estabelecer hábitos de consumo ${ }^{5}$. Para tanto são apresentados como instrumentos de pesquisas: cyberinterviews, e-mails, board postings, e homepages.

Entusiastas do método de etnografia online (outro nome encontrado), autores como Rutter \& Smith, enaltecem o favorecimento de ferramentas tecnológicas para o desenvolvimento de pesquisas. Segundo os autores,

"Online ethnography is surely a researchers dream. It does not involve leaving the comforts of your office desk; there are no

\footnotetext{
${ }^{4}$ As aplicações do estudo do pesquisador Robert Kozinets ocorrem basicamente relacionadas aos hábitos dos consumidores virtuais (cibermarketing). Netnography presents "a fusion of established and innovative ethnographic techniques adapted to the naturalistic study of virtual communities, and their research representation" striving for the profound experiencing of digital sociality (Sherry and Kozinets 2000). ${ }^{5}$ Encontrou-se no endereço www.mngt.waikato.ac.nz/research/ejrot/cmsconference/2003/proceedings/criticalmar keting/Maclaran, o seguinte texto Gender, Technology And Computer-Mediated Communications In Consumption-Related Online Communities Stream 23: Critical Marketing: Visibility, Inclusivity, Captivity Pauline Maclaran, De Montfort University, Leicester, England, Miriam Catterall, The Queen's University of Belfast, N.Ireland, Margaret Hogg, Manchester School of Management, UMIST, England Rob Kozinets, Northwestern University, USA
} 
complex acess privileges to negotiate; field data can be easily recorded and saved for later analysis (...) Doubtless Malinowski or Whyte would have been appalled by the ease with the online version of their craft can be done" (Rutter \& Smith, 2002).

No Brasil, um dos estudos recentes sobre o tema é da pesquisadora Simone Pereira de Sá, cujo texto "Netnografias nas redes digitais" privilegia esta prática ao escolher "uma metodologia assumidamente focal, experimental, detalhista e interpretativa, que se reconhece como fruto de uma "negociação construtiva" entre o pesquisador e o pesquisado durante relações concretas, intensivas e "carnais", permeada por sentimentos, emoções, afetos, surpresas e incertezas nos encontros, festas, ensaios de quadra e desfiles durante o Carnaval. Para tanto a pesquisadora realiza monitoramento de sites relacionados à comunidade carnavalesca que é seu objeto de pesquisa, seu local de observação.

As distorções quanto à etnografia do virtual em relação ao aspecto de facilidade ao não precisar deslocamento físico, não são plausíveis no discurso de muitos pesquisadores que acreditam que o processo configura-se como intermittent engagement.

Faz-se importante ressaltar que a preocupação deste artigo, ao apresentar, algumas aplicações do método é a reflexão quanto ao caráter relevante da tecnologia na sociedade contemporânea. Não apenas as facilidades surgidas com o meio internet, mas suas implicações na vida real, seja online ou offline. Assim como diz Christhine Hine, “(...) This presents an opportunity for rethinking the shaping of the ethongraphic object and reformulating the grounds for ethnographic engagement with the field" (HINE, 2000, 10). Nota-se que a pesquisadora, Hine, é amplamente vinculada a pesquisas no ciberespaço devido ao seu interesse no tema desde meados dos anos 90. O livro Virtual Ethnography, 2000, é referência em termos de aplicação de técnicas quanto ao estudo de comunidade virtuais. 
O debate sobre a cibercultura com a interface da comunicação se estrutura em torno da inserção das tecnologias de informação e de comunicação no mundo contemporâneo, de forma a contemplar questões relativas à comunicação mediada por computador, bem como à sua influência na indústria de comunicação e na sociedade. Exemplos nesse sentido podem ser dados pela grande popularidade de programas de comunicadores instantâneos (Mirc, ICQ, MSN) e pelas redes sociais de comunicação (Orkut, Likedin, Multiply, MySpace, Tribenet, e os brasileiros Gazzag, 1Grau, Link, Beltrano, etc.) $)^{5}$.

Ao falar da economia da atenção no ciberespaço, por exemplo, Lévy (2004) mostra a sua visão sobre as oportunidades de negócios percebidas na Internet (cibermarketing) nos seguintes termos:

\footnotetext{
5 Abordagens dessas temáticas podem ser fornecidas por estudos sobre comunidades virtuais, a partir de texto fundador de Howard Rheingold (The Virtual Community, 1993), do livro de entrevistas de Federico Casalegno (Memória cotidiana. Comunidade e comunicação na era das redes, no prelo), e de aplicações dessas e de outras teorias pela pesquisadora Raquel Recuero (Comunidades virtuais na Internet. O caso de Pelotas. Um estudo de como a comunicação mediada por computador está alterando a sociabilidade humana, 2002).
}

${ }^{6}$ Segundo o site do IBOPE, o IBOPE//NetRatings é uma joint-venture entre o IBOPE e a Nielsen//NetRatings, líder mundial em medição de audiência de Internet. Com o auxílio de um software proprietário, instalado em um painel de internautas representativo da população domiciliar brasileira com acesso à Web, a empresa detalha o comportamento dos usuários do meio digital. Além da atuação no Brasil, a Nielsen//NetRatings está presente em outros 12 países, utilizando o mesmo rigor metodológico e capacidade tecnológica que permitem fornecer os dados mais completos, precisos e amplos sobre a utilização da Internet. 


\begin{abstract}
Um imenso hipertexto criado com todas as subjetividades, o ciberespaço dá hoje um corpo virtual à consciência coletiva. É aí, portanto, nesse lugar sem distâncias físicas, que terá lugar a competição entre as empresas planetárias e, cada vez mais, entre as empresas locais. O nervo do comércio se torna o tráfego da atenção no ciberespaço. (LÈVY, 2004, p. 177)
\end{abstract}

De maneira mais direta, o autor se refere a alguns movimentos da dinâmica do que chama de cibermarketing:"a popularidade dos sites comerciais é organizada por meio de uma hábil indexação nos motores de busca, pela tessitura dos hiperlinks que apontam para eles, pela animação de comunidades virtuais que gravitam em torno de seus temas" (LÈVY, 2004, p. 178).

Uma pesquisa realizada pelo Ibope // NetRatings ${ }^{6}$ revelou que em maio desse ano, o Brasil passou à frente de Estados Unidos, França e Japão em horas de navegação por mês (16h55), conforme matéria da Revista Meio e Mensagem. A mesma matéria afirma que, de acordo com a apuração do National Institute for Technology and Liberal Education (Nitle), que classifica os blogs de acordo com o idioma, a língua portuguesa ficou em terceiro lugar em quantidade de blogs (81.077 blogs). Outro dado interessante é o aumento do acesso à Internet entre as camadas D e E (7\% em abril de 2004 para 11\% em junho de 2005), conforme o relatório do $17^{\circ}$. Internet Pop, sendo que os principais locais de acesso são escola, trabalho e casa de amigos e parentes (apenas $4 \%$ acessa de casa). De acordo com matéria veiculada no Jornal O Globo, a PricewaterhouseCoopers atribui a maior incidência do uso da Internet à oferta cada vez maior de banda larga para uso doméstico.

Ainda segundo essa matéria, a Interactive Advertising Bureau (IAB) e a PricewaterhouseCoopers (PWC), indicam que os anúncios via web movimentaram só no primeiro trimestre desse ano $\mathrm{U} \$ \mathrm{~S} 2,8$ bilhões, contra U\$S 2,2 bilhões no mesmo período do ano passado nos Estados Unidos. Com esses números, atesta-se o nono trimestrte consecutivo de crescimento de investimentos na Internet. Já no Brasil, uma apuração realizada pelo 
Ibope/Intermeios, indica que os investimentos publicitários em Internet no ano de 2004 perfazem $3 \%$ do total dos meios de comunicação.

Frente a isso, é fácil perceber que cada vez mais ações publicitárias e de marketing se complementam de maneira mais direta na Internet (um anúncio pode resultar em um preenchimento de cadastro ou, até mesmo, levar a uma compra) devido ao caráter interativo desse meio de comunicação. De qualquer forma, Lévy (2005), em coro com outros, acerta quando afirma que:

o principal problema é cada vez mais é atrair, canalizar, estabilizar a atenção. E ocorre que a melhor forma de polarizar a atenção, em um mercado tão livre e aberto quanto o ciberespaço é prestar serviço, escutar exatamente o que querem as pessoas sonho, amor, jogos, saber, mercadorias de todos os tipos - e dar isso a elas . Senão, elas irão para outro lugar, muito rápido, num só clique. (LÈVY, 2004, p. 179)

O interesse das empresas pela Internet pode se dar de outra maneira: a busca de informações a respeito do que é dito sobre sua marca. Isso porque a intensificação do uso dos comunicadores instantâneos e das redes sociais de comunicação ampliaram o leque de opções nesse sentido. Gustavo Donda, diretor de criação da TV1.Com, resume a situação do seguinte modo:

\begin{abstract}
O internauta brasileiro encontrou (e adotou) um ambiente no qual é capaz de se expressar de forma livre e muito rápida, além de agremiar uma legião de fãs. Um anônimo ganha status de conselheiro após apenas alguns posts. O que deve ser lembrado é que nem tudo são flores para as marcas. Existem comunidades criadas para idolatrar determinados produtos, e outras, ainda maiores, para achacá-los. (Donda, 2005, p. 37)
\end{abstract}

Diante disso, a sugestão é de se lance reviews, sites através dos quais as marcas ouvem a crítica de clientes descontentes com a marca em questão. Outra medida que vem sendo adotada pelas empresas na definição de seu planejamento estratégico é a monitoração de weblogs para a detecção de opiniões a respeito da marca. Quanto a isso, em matéria de Luiz Santos, veiculada pela Revista Meio \& Mensagem, Alessandro Barbosa Lima, pesquisador da área acadêmica e sócio da empresa de consultoria de marketing e.life, que atua no segmento de $w e b$, entende que: "a tecnologia da 
informação está criando uma nova categoria de formadores de opinião. Compreender a dinâmica desse fenômeno é fundamental para qualquer empresa se movimentar em meio à transformação de um modelo de comunicação de massa para um outro, o de microaudiência". (Lima citado por SANTOS, 2005, p. 34).

Em entrevista à Revista Exame, o conselho de Steve Rubel, maior autoridade do mundo em blogs, vai no mesmo sentido do que o de Alessandro Barbosa Lima. O executivo norte-americano que trabalha atualmente na firma de Relações Públicas CooperKatz, perante os comentários negativos sobre seus clientes encontrados nos blogs, planeja estratégias para minimizar o prejuízo, ressaltando que é preciso utilizar essa ferramenta a seu favor. IBM, GM e Microsoft estão entre as grandes empresas que prestam atenção ao que os blogs dizem, não somente para evitar crises, mas também para criar oportunidades.

Pode-se dizer que a Internet já faz parte da vida de muitos brasileiros e tende a se popularizar ainda mais. Essa seção buscou ilustrar essa situação, de modo a contemplar dados que forneçam indícios desse uso, as práticas que estão sendo aplicadas pelo mercado publicitário e corporativo como um todo, além do tratamento teórico que a questão vem recebendo. O próximo item retoma o objetivo principal e ressalta a justificativa deste artigo.

\section{Considerações finais}

O que se pretendeu com as observações feitas até aqui foi a problematização da questão metodológica quando se trata de objetos da cibercultura. O debate deve-se ao fato de que este artigo veio à tona a partir de discussões em torno de aspectos metodológicos de particularmente dois trabalhos. Uma pesquisa sobre publicidade e interatividade na internet e também de uma tese de doutorado que está sendo feita a respeito da construção da linguagem do jornalismo on-line. Ressalta-se que as duas pesquisas passaram pelo momento, considerado, netnográfico, ou seja, de 
imersão na rede, porém que o trabalho de jornalismo on-line precisou de um deslocamento físico que compreende uma observação in loco, etnográfica. Portanto as considerações da autora Sherry Turkle (1995), de que os dados virtuais devem ser comparados com os reais (ou presenciais), neste caso, foram pertinentes.

Conforme o texto mostrou, o tema já está presente tanto em artigos científicos das áreas da antropologia, sociologia e comunicação bem como em matérias revistas especializadas no mercado de comunicação (Jornalismo, Relações Públicas, Publicidade e Propaganda e Marketing). Pode-se dizer que é nas ações relativas ao planejamento de marketing de grandes empresas que a netnografia vem sendo aplicada com maior freqüência e que no mundo acadêmico se observa, particularmente, em pesquisadores de língua inglesa, uma preocupação quanto à aplicação dos métodos da etnografia virtual.

Acredita-se que a relevância desta discussão possa ser de interesse de vários pesquisadores, cujos objetos de estudo estejam localizados em alguma materialização da cibercultura. Em tempos de crescentes contatos no ciberespaço parece importante uma observação do antropólogo Clifford Geertz (2001) que diz que o termo local é "relativo", uma vez que se deve considerar o ponto de vista de quem observa, pois "no sistema solar, a Terra é local (...), na galáxia, o sistema solar é local (A Voyager deve ajudar nisso); e no universo, a galáxia é local” (GEERTZ, 2001, p. 124).

Portanto, a situação atual de deslocamento, de globalização, de fluxo de informações, de transição de modernidade para pós-modernidade, de distorções de termos como local, global e glocal interferem diretamente no critério metodológico a ser selecionado para investigações desse tipo. E ainda a validade da etnografia na contemporaneidade na observação de manifestações de formas da cibercultura, merece um aprofundamento que leve em conta a possibilidade de olhar o objeto, de aproximar-se dele de modo 
virtual, on-line e netnográfico, mas também, quando existir a chance, de modo presencial.

\section{Referências:}

AUGÉ, Marc. Não-lugares. Introdução a uma antropologia da supermodernidade. 3 ed. Campinas, SP: Papirus, 1994.

BAZTÁN, Aguirre. Etnografía. Metodologia cualitativa em la investigación sociocultural. Barcelona: Editorial Boixareu Universitária, 1995.

CASALEGNO, Federico. Memória cotidiana. Comunidade e comunicação na era das redes. (No prelo).

DAMATTA, Roberto. Relativizando. Uma introdução à antropologia social. Rio de Janeiro: Rocco, 1987.

DONDA, Gustavo. O Orkut e as marcas in: Meio \& Mensagem. São Paulo, Editora Referência, p. 37, 21 de março de 2005.

FUENTES NAVARRO, Raul. El estudio de la comunicación desde una perspectiva sociocultural en América Latina in: Diá-logos de la comunicación, Peru, n.49, p. 16-25, 1994.

. Hacia una investigación posdisciplinaria de la comunicación, Revista Telos, Madri, n 47, p.9-11, set-nov 1996.

Retos disciplinarios y postdisciplinarios para la investigación de la comunicación, Comunicación y Sociedad, Guadalajara, n. 31, p. 215-241, set-dec1997.

GEERTZ, Clifford. Nova luz sobre a antropologia. Rio de Janeiro: Jorge Zahar, 2001.

GIESLER, Markus;POHLMANN, Mali. The Anthropology of File Sharing: Consuming Napster as a Gift, 2001. Disponível em: www.mymacexperience.com/GieslerGift.pdf. Acesso em 18 de agosto de 2005 .

IANNI, Octavio. A sociedade global. Rio de Janeiro: Civilização Brasileira, 2002. 
Ibope Net//Ratings. Disponível em www.ibope.com.br. Acessado em 11 de agosto de 2005.

JONES, Steve. Doing internet research: critical issues and methods for examining the net. Sage Publications, 1998.

\section{KOZINETS, Robert V. What Can Anthropology Add to Marketing?,} 2002. Disponível em gsbwww.chicagogsb.edu/kilts/research/workshop/WorkshopPapers/Uni versityofChicago_Present.pdf. Acesso em 26 de agosto de 2005.

The Field Behind the Screen: Using Netnography for Marketing Research in Online Communities, 2002, Disponível em: http://www.marketingpower.com/content18255.php. Acesso em 3 de agosto de 2005.

LEMOS, André. Anjos interativos e retribalização do mundo: sobre Interatividade e Interfaces Digitais, 1997. Disponível em:

<http://www.facom.ufba.br/ciberpesquisa/lemos/interativo.pdf >.Acesso em: 09 mai. 2005.

LÉVY, Pierre. O ciberespaço e a economia da atenção in: PARENTE, André (org.). Tramas da rede. Novas dimensões filosóficas, estéticas e políticas da comunicação. Porto Alegre: Sulina, 2004.

MANN, Chris. Internet communication and qualitative research: a handbook for researching online. Sage Publications, 2000.

MARTINO, Luís Cláudio. Ceticismo e interdisciplinaridade: paradoxos e impasses da teoria da comunicação. In: XIV COMPÓS, 2005, Niterói. Anais. Niterói: COMPÓS, 2005. Disponível em cd-rom.

MATTELART, Armand e Michelle. História das teorias da comunicação. São Paulo: Loyola, 1999.

Method based on Kozinets, 2002. Disponível http://www.ciadvertising.org/SA/spring_04/adv391k/karen/NetnoMeth od.htm. Acesso em 3 de agosto de 2005.

MONTARDO, Sandra Portella; ROCHA, Paula Jung. Cartografia da utilização da mídia no espaço virtual em Novo Hamburgo: proposta de referencial teórico in: Gestão e Desenvolvimento. Novo Hamburgo: Feevale, 2005 (no prelo).

PIMENTA, Ângela. Faça do blog um aliado. Entrevista com Steve Rubel in: Revista Exame. São Paulo, Editora Abril, p. 116, 20 de julho de 2005.

RECUERO, Raquel. Comunidades virtuais na Internet. $O$ caso de

Pelotas. Um estudo de como a comunicação mediada por computador está alterando a sociabilidade humana. Porto Alegre, UFRGS, 2002.

Dissertação. (Mestrado em Comunicação Social), FABICO, UFRGS, 2002. 
RHEINGOLD, Howard. A comunidade virtual. 1 ed. Lisboa: Gradiva, 1996.

SÁ, Simone Pereira de. Netnografias nas redes digitais. Trabalho apresentado ao Grupo de Trabalho Tecnologias Informacionais de Comunicação e Sociedade, X Compós, UnB, Brasília, 2001.

SANTOS, Luiz. Burburinho de marcas. In: Meio\&Mensagem. São Paulo, Editora Referência, p. 34, 11 de julho de 2005.

TURKLE, S. Life on the screen:identity in the age of the internet. Toronto, 1995.

VASCONCELOS, Nelson. Publicidade.br in: Jornal O Globo, 15 de junho de 2005 .

VIZER, Eduardo. Categorias compartidas entre la comunicación y el análisis social in: In: XIV COMPÓS, 2005, Niterói. Anais. Niterói: COMPÓS, 2005. Disponível em cd-rom. 